\title{
An exploration study to detect different factors influencing on inefficiency of office automation systems
}

\author{
Azam Roostaee* and Jamshid Salehi Sadaghiani
}

Department of Management, Allameh TabaTabayi University Tehran, Iran

\begin{tabular}{l}
\hline C H R O N I C L E \\
\hline Article history: \\
Received January 10, 2013 \\
Received in revised format \\
10 April 2013 \\
Accepted 12 May 2013 \\
Available online \\
May 142013 \\
\hline Keywords: \\
Office automation system \\
Ministry of Science, Research and \\
Technology \\
Efficiency
\end{tabular}

A B S T R A C T

\begin{abstract}
Office automation systems play important role on increasing productivity and efficiency of organizations. An automated system is capable of improving required communications, speed up the process of tasks and removes unnecessary activities. This paper presents an empirical investigation to detect important factors influencing on inefficiency of office automation systems in ministry of science, research and technology of Iran. The proposed study of this paper designs a questionnaire and distributes it among management team who work for this organization. The results of our investigation indicate that two factors, lack of necessary infrastructure for participating in office automation activities as well as lack of management support, play important role on reaching desirable results. In addition, educational background and work experience also influence office automation systems’ applicability.
\end{abstract}

\section{Introduction}

Office automation systems play important role on increasing productivity and efficiency of organizations. An automated system is capable of improving required communications, speed up the process of tasks and removes unnecessary activities. During the past two decades, many governmental or non-governmental firms around the world have tried to computerize their administrative tasks. Many job applications are filed through web-based applications. People file their yearly income tax based on internet facilities. These days, when an official letter arrives to an organization, it will be first scanned and uploaded into a computer program and next it will be circulated within the organization. This would help all interested parties to read the letters and take the necessary actions, promptly. The circulation of these kinds of information seems to be easy through availability of intranet systems. However, there are some evidences, which indicate that there were some challenges facing office automation systems. Some users complain that office automation systems are difficult to use, the others find them full of flaws and some other people prefer traditional

Corresponding author.

E-mail: phd_roostaee@yahoo.com (A. Roostaee)

(C) 2013 Growing Science Ltd. All rights reserved. doi: 10.5267/j.msl.2013.05.016 
systems to modern automated ones. Nevertheless, when an efficient system proves to work in the system, it will improve efficiency of organization, significantly. Measuring the efficiency of organization, on the other hand, plays an essential role in todays' competitive world.

Roghanian and Foroughi (2010) used data envelopment analysis (DEA) (Charnes et al., 1978) to measure the relative efficiency of airports. Khaki et al. (2012) developed a ranking method based on the Indicator with Limited Sources (ILS) for the efficient decision making units, when there is changes either in inputs/ outputs ILS. The implementation of the proposed model is applied for a case study of banking system. Balanced score card (BSC) is another method for measuring the performance of organizations, which was originally developed by Kaplan and Norton (Kaplan \& Norton, 1996, 2000, 2004). There are many applications of BSC methods for measuring the success of the systems in terms of four perspectives including internal processes (Mozaffari et al., 2012). Zhou et al. (2011) performed an investigation to identify critical success factors in emergency management using a fuzzy DEMATEL method.

\section{The proposed study}

The proposed study of this paper considers different factors influencing on inefficiency of office automation systems in ministry of science, research and technology of Iran. We design a questionnaire and distribute it among management team who work for this organization. The proposed study considers three different factors influencing the efficiency of office automation systems including the factors associated with individual users, the factors related to management teams; and finally technical factors associated with the system. The proposed study uses the following equation is used to calculate the sample size,

$$
n=\frac{N \times z_{\alpha / 2}^{2} \times p \times q}{\varepsilon^{2} \times(N-1)+z_{\alpha / 2}^{2} \times p \times q},
$$

where $N$ is the population size, $p=1-q$ represents the yes/no categories, $z_{\alpha / 2}$ is CDF of normal distribution and finally $\varepsilon$ is the error term. Since we have $p=0.5, z_{\alpha / 2}=1.96$ and $N=98$, the number of sample size is calculated as $n=70$. Table 1 summarizes some of the main barriers of using automation system.

\section{Table 1}

The summary of different barriers for having efficient office automation

\begin{tabular}{llll}
\hline Item & Reason & Type & Frequency \\
\hline 1 & Unfamiliarity of users with computers and related software packages & Personal & 32 \\
2 & Designing inappropriate system & Technical & 43 \\
3 & Lack of attention for training before installation & Management & 52 \\
4 & Lack of motivation to use modern systems compared with traditional ones & Personal & 26 \\
5 & Fast management change & Management & 48 \\
6 & Lack of users' participations in the design and development of systems & Management & 37 \\
7 & Designed system is not attractive & Technical & 27 \\
8 & Lack of personal motivation to use the system & Personal & 29 \\
9 & Designing the system without paying enough attention to users & Technical & 32 \\
10 & Low processing time & Technical & 44 \\
11 & Lack of a good management in design stage & Management & 49 \\
12 & Lack of interest among employees to use the system & Personal & 34 \\
13 & Lack of support on behalf of management team & Management & 49 \\
14 & Using the automation system is time consuming & Personal & 33 \\
15 & Facing with complicated system & Technical & 23 \\
\hline
\end{tabular}

We first select a group of 20 people to verify the questionnaire and Cronbach alpha has been calculated as 0.69 , which fairly approves the questionnaire. In our survey, 31 participants were female and 39 of them were male. In terms of educational background, 30 people, representing 
$42.9 \%$, hold bachelor of science and 44 people representing $62.9 \%$ of the participants had social science educations. In addition, 53 people representing $75.7 \%$ of the participants had between 11 to 20 years of job experience.

As we can observe from the results of Table 1, Lack of attention for training before installation seems to be the most important item and facing with complicated system appears to be the least important item.

\section{The results}

\subsection{Personal barriers}

In this section, we present details of our findings in terms of personal factors. Fig 1 shows details of the responses for personal factors.

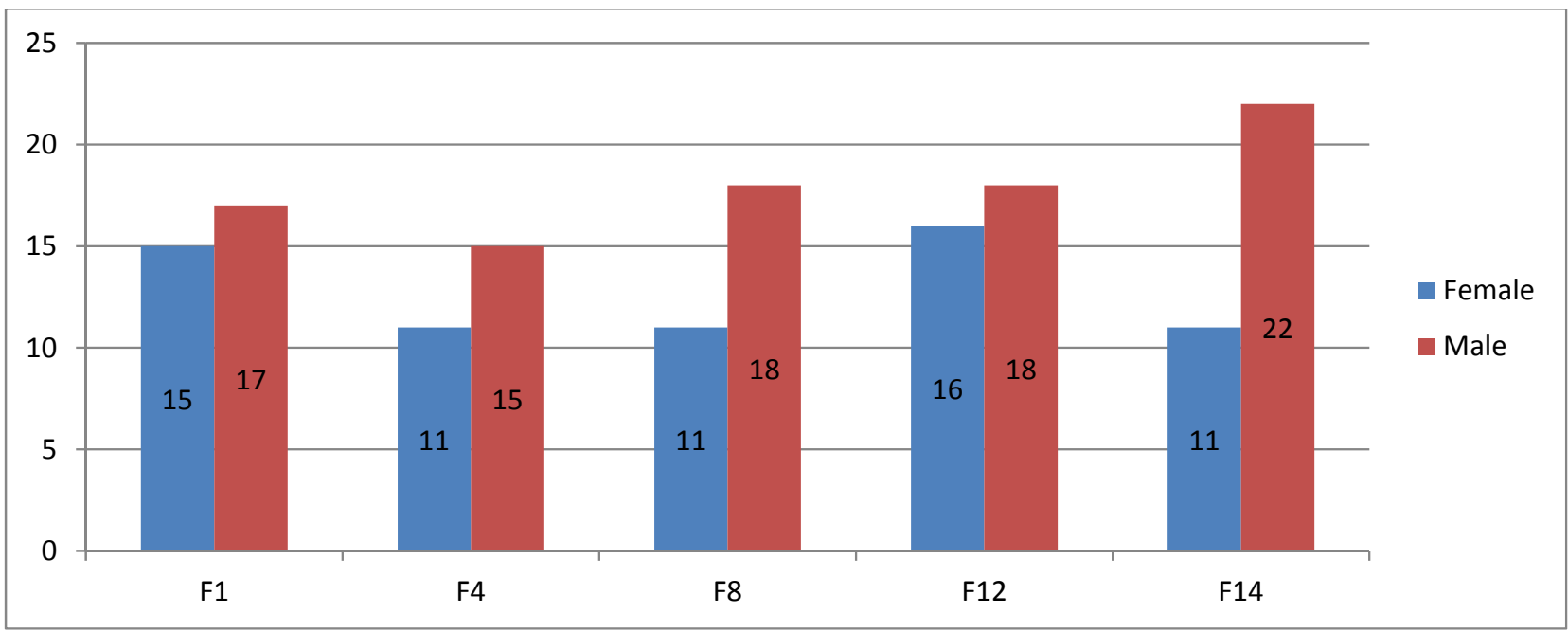

Fig. 1. The frequency of answers to personal questions

As we can observe, lack of interest to use computer system is the most important personal factor and interest in using traditional system has received the lowest point. In addition, we have performed a Chi-square test to verify whether the numbers are randomly selected or not. Table 2 shows details of our survey,

Table 2

The results of Chi-Square for personal barriers

\begin{tabular}{lccccc}
\hline & F1 & F4 & F8 & F12 & F14 \\
\hline Chi-square & 13.829 & 27.457 & 20.064 & 10.314 & 12.007 \\
df & 1 & 1 & 1 & 1 & 1 \\
Asump. Sig. & 0.000 & 0.000 & 0.000 & 0.000 & 0.001 \\
\hline
\end{tabular}

As we can observe from the results of Table 2, all null hypotheses are rejected and we can conclude that the figures are not randomly distributed.

\subsection{Management barriers}

The second item is associated with management factors and Fig 2 shows details of the responses for these factors. 


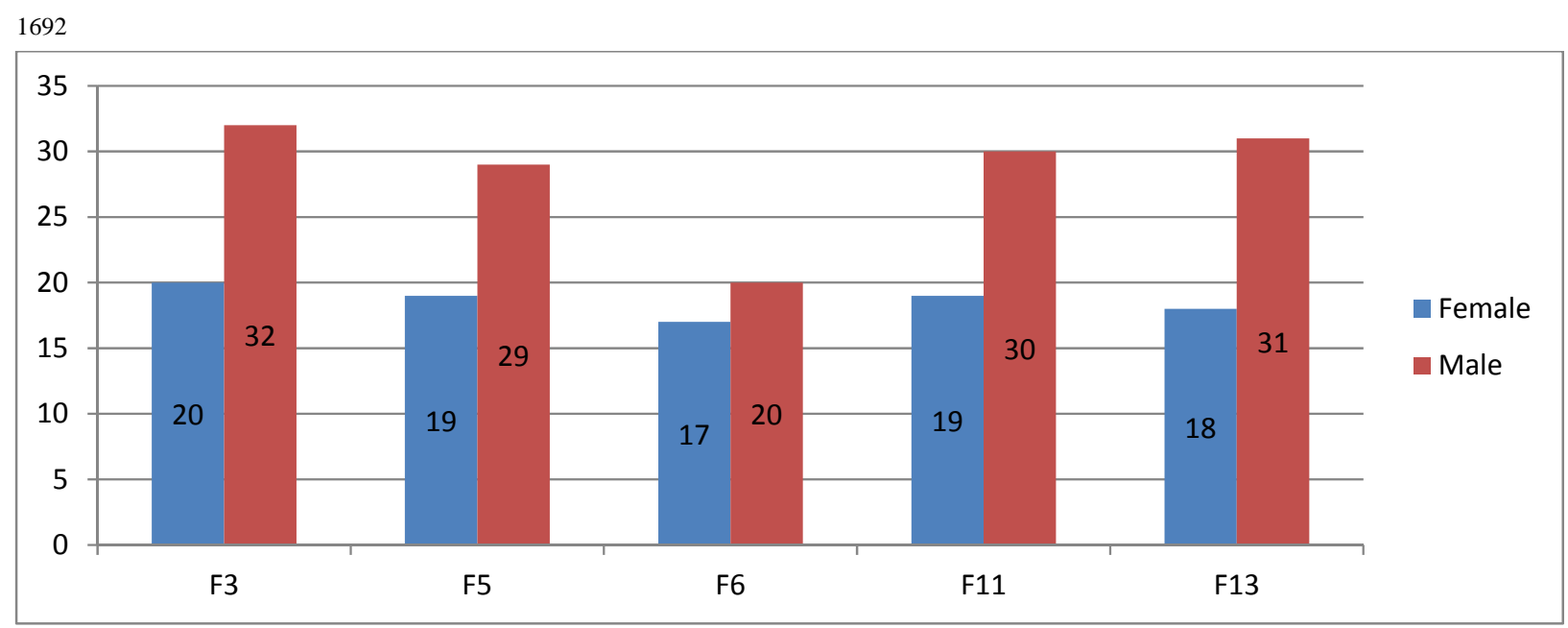

Fig. 2. The frequency of answers to management related questions

As we can observe from the results of Fig. 2, the third factor (F3), which is the lack of attention for training before installation is the most important managerial factor and lack of users' participations in the design and development of systems, F6, has received the lowest point. In addition, we have performed a Chi-square test to verify whether the numbers are randomly selected or not. Table 3 shows details of our survey,

Table 3

The results of Chi-Square for management type barriers

\begin{tabular}{lccccc}
\hline & F3 & F5 & F6 & F11 & F13 \\
\hline Chi-square & 16.514 & 9.657 & 0.229 & 12.200 & 11.200 \\
df & 1 & 1 & 1 & 1 & 1 \\
Asump. Sig. & 0.000 & 0.002 & 0.633 & 0.001 & 0.001 \\
\hline
\end{tabular}

As we can observe from the results of Table 3, all null hypotheses, except the case associated with F6, have been rejected and we can conclude that the figures are not randomly distributed.

\subsection{Technical barriers}

Finally, the third item is associated with technical factors and Fig 3 demonstrates details of the responses for these factors.

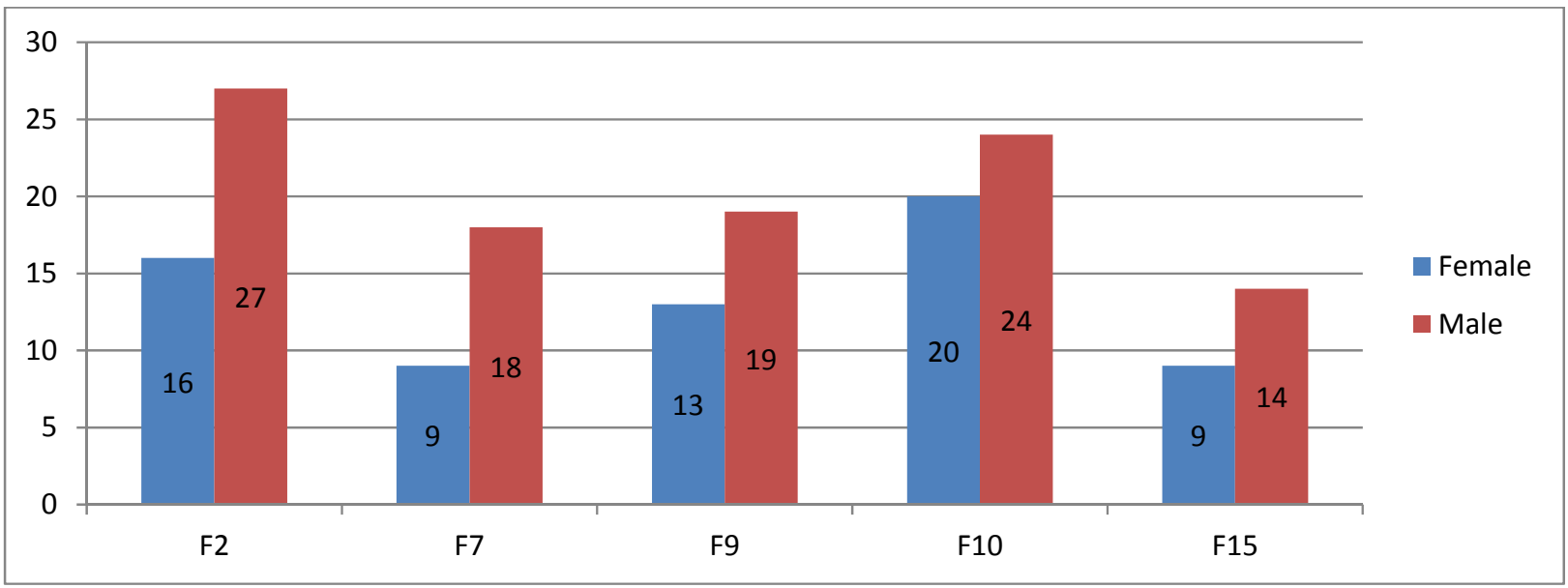

Fig. 3. The frequency of answers to technical based barriers 
As we can observe from the results of Fig. 3, the third factor (F10), which is associated with inefficient and slow software package is the most important technical factor and Facing with complicated system, F15, has received the lowest point. In addition, we have performed a Chi-square test to verify whether the numbers are randomly selected or not. Table 4 presents details of our survey,

Table 4

The results of Chi-Square for technical factors

\begin{tabular}{lccccc}
\hline & F2 & F7 & F9 & F10 & F15 \\
\hline Chi-square & 0.864 & 24.864 & 13.829 & 0.457 & 36.007 \\
df & 1 & 1 & 1 & 1 & 1 \\
Asump. Sig. & 0.353 & 0.000 & 0.000 & 0.499 & 0.000 \\
\hline
\end{tabular}

As we can observe from the results of Table 4, all null hypotheses, except the case associated with F2 and F10, have been rejected and we can conclude that the figures are not randomly distributed.

In summary, it appears that managerial barriers are blamed the most followed by technical challenges and personal factor.

\subsection{The effect of gender}

We have also used Chi-Square test to understand whether gender plays an important role on using office automation systems or not. Table 5 demonstrates the results of our survey as follows,

Table 5

The summary of Chi-Square for the effect of gender

\begin{tabular}{|c|c|c|c|c|c|c|c|c|}
\hline & & \multicolumn{2}{|c|}{ Personal } & \multicolumn{2}{|c|}{ Technical } & \multicolumn{2}{|c|}{ Management } & \multirow[b]{2}{*}{ Total } \\
\hline & & Not selected & Selected & Not selected & Selected & Not selected & Selected & \\
\hline \multirow[t]{2}{*}{ Female } & Count & 91 & 64 & 88 & 67 & 70 & 85 & 155 \\
\hline & $\%$ & $58.7 \%$ & $41.3 \%$ & $58.8 \%$ & $43.2 \%$ & $45.2 \%$ & $54.8 \%$ & $100 \%$ \\
\hline \multirow[t]{2}{*}{ Male } & Count & 105 & 90 & 93 & 102 & 45 & 150 & 195 \\
\hline & $\%$ & $53.8 \%$ & $46.2 \%$ & $47.7 \%$ & $52.3 \%$ & $23.1 \%$ & $76.9 \%$ & $100 \%$ \\
\hline \multirow[t]{2}{*}{ Total } & Count & 196 & 154 & 181 & 169 & 115 & 235 & 350 \\
\hline & $\%$ & $56.0 \%$ & $44.0 \%$ & $51.7 \%$ & $48.3 \%$ & $32.9 \%$ & $67.1 \%$ & $100 \%$ \\
\hline
\end{tabular}

In addition, Table 6 demonstrates the results of applying Chi-Square test.

\section{Table 6}

The results of Chi-Square test for the effect of gender

\begin{tabular}{|c|c|c|c|c|c|c|c|c|c|}
\hline & \multicolumn{3}{|c|}{ Personal } & \multicolumn{3}{|c|}{ Technical } & \multicolumn{3}{|c|}{ Management } \\
\hline & Value & df & Sig. (2-sided) & Value & df & Sig. (2-sided) & Value & df & Sig. (2-sided) \\
\hline Pearson Chi-Square & 0.829 & 1 & 0.363 & 2.852 & 1 & 0.091 & 19.091 & 1 & 0.000 \\
\hline Continuity correction & 0.643 & 1 & 0.422 & 2.500 & 1 & 0.114 & 18.104 & 1 & 0.000 \\
\hline Likelihood Ratio & 0.830 & 1 & 0.362 & 2.858 & 1 & 0.091 & 19.112 & 1 & 0.000 \\
\hline $\begin{array}{l}\text { Linear-by-Linear } \\
\text { Association }\end{array}$ & 0.827 & 1 & 0.363 & 2.844 & 1 & 0.092 & 19.037 & & 0.000 \\
\hline $\mathrm{N}$ of Valid Cases & 35 & & & 350 & & & 350 & & \\
\hline
\end{tabular}

The results of Table 6 indicate that personal and technical barriers have no correlations with gender but management barriers and gender are correlated when the level of significance is five percent. 


\subsection{The effect of work experience}

Another important factor is associated with the relationship between different barriers and work experience. Table 7 demonstrates the results of our survey on the effect of work experiences as follows,

\section{Table 7}

The summary of Chi-Square for the effect of work experience

\begin{tabular}{|c|c|c|c|c|c|c|c|c|}
\hline \multirow{2}{*}{\multicolumn{2}{|c|}{$\begin{array}{l}\text { Work } \\
\text { experience }\end{array}$}} & \multicolumn{2}{|c|}{ Personal } & \multicolumn{2}{|c|}{ Technical } & \multicolumn{2}{|c|}{ Management } & \multirow[b]{2}{*}{ Total } \\
\hline & & Not selected & Selected & Not selected & Selected & Not selected & Selected & \\
\hline \multirow[t]{2}{*}{$1-10$} & Count & 56 & 34 & 32 & 58 & 37 & 54 & 90 \\
\hline & $\%$ & $62.2 \%$ & $37.8 \%$ & $35.6 \%$ & $64.4 \%$ & $40.7 \%$ & $40.7 \%$ & $100 \%$ \\
\hline \multirow[t]{2}{*}{$11-20$} & Count & 122 & 93 & 122 & 93 & 65 & 149 & 215 \\
\hline & $\%$ & $56.7 \%$ & $43.3 \%$ & $56.7 \%$ & $43.3 \%$ & $30.4 \%$ & $69.6 \%$ & $100 \%$ \\
\hline \multirow[t]{2}{*}{$>21$} & Count & 18 & 27 & 27 & 18 & 13 & 32 & 45 \\
\hline & $\%$ & $40.0 \%$ & $60.0 \%$ & $60.0 \%$ & $40.0 \%$ & $28.9 \%$ & $71.1 \%$ & $100 \%$ \\
\hline \multirow[t]{2}{*}{ Total } & Count & 196 & 154 & 181 & 169 & 115 & 235 & 350 \\
\hline & $\%$ & $56.0 \%$ & $44.0 \%$ & $51.7 \%$ & $48.3 \%$ & $32.9 \%$ & $67.1 \%$ & $100 \%$ \\
\hline
\end{tabular}

In addition, Table 8 demonstrates the results of applying Chi-Square test.

\section{Table 8}

The results of Chi-Square test for the effect of job experience

\begin{tabular}{|c|c|c|c|c|c|c|c|c|c|}
\hline & \multicolumn{3}{|c|}{ Personal } & \multicolumn{3}{|c|}{ Technical } & \multicolumn{3}{|c|}{ Management } \\
\hline & Value & $\mathrm{df}$ & Sig. (2-sided) & Value & df & Sig. (2-sided) & Value & df & Sig. (2-sided) \\
\hline Pearson Chi-Square & 6.138 & 2 & 0.046 & 12.826 & 2 & 0.002 & 3.430 & 2 & 0.180 \\
\hline Likelihood Ratio & 6.116 & 2 & 0.047 & 12.944 & 2 & 0.002 & 3.360 & 2 & 0.180 \\
\hline $\begin{array}{l}\text { Linear-by-Linear } \\
\text { Association }\end{array}$ & 5.131 & 1 & 0.023 & 10.317 & 1 & 0.001 & 2.746 & 1 & 0.097 \\
\hline $\mathrm{N}$ of Valid Cases & 350 & & & 350 & & & 350 & & \\
\hline
\end{tabular}

The results of Table 8 indicate that personal and technical barriers have meaningful correlations with job experience but management barriers and job experience is not correlated when the level of significance is five percent.

\subsection{The effect of educational background}

The other important factor is associated with the relationship between different barriers and educational background. Table 9 presents details of the results of our survey on the effect of educational background as follows,

Table 9

The summary of Chi-Square for the effect of educational background

\begin{tabular}{|c|c|c|c|c|c|c|c|c|}
\hline \multirow{2}{*}{$\begin{array}{l}\text { Work } \\
\text { experience }\end{array}$} & & \multicolumn{2}{|c|}{ Personal } & \multicolumn{2}{|c|}{ Technical } & \multicolumn{2}{|c|}{ Management } & \multirow[b]{2}{*}{ Total } \\
\hline & & Not selected & Selected & Not selected & Selected & $\begin{array}{l}\text { Not } \\
\text { selected }\end{array}$ & Selected & \\
\hline \multirow{2}{*}{$\begin{array}{l}\text { Social } \\
\text { science }\end{array}$} & Count & 110 & 110 & 119 & 102 & 68 & 152 & 220 \\
\hline & $\%$ & $50.0 \%$ & $50.0 \%$ & $53.8 \%$ & $46.2 \%$ & $30.9 \%$ & $69.1 \%$ & $100 \%$ \\
\hline \multirow{2}{*}{$\begin{array}{l}\text { Basic } \\
\text { science }\end{array}$} & Count & 31 & 14 & 24 & 21 & 15 & 30 & 45 \\
\hline & $\%$ & $68.9 \%$ & $31.1 \%$ & $53.3 \%$ & $46.7 \%$ & $33.3 \%$ & $66.7 \%$ & $100 \%$ \\
\hline \multirow[t]{2}{*}{ Engineering } & Count & 37 & 18 & 19 & 36 & 11 & 38 & 49 \\
\hline & $\%$ & $67.3 \%$ & $32.7 \%$ & $34.5 \%$ & $65.5 \%$ & $22.4 \%$ & $77.6 \%$ & $100 \%$ \\
\hline \multirow[t]{2}{*}{ Art } & Count & 18 & 12 & 19 & 10 & 21 & 15 & 36 \\
\hline & $\%$ & $60.0 \%$ & $40.0 \%$ & $65.5 \%$ & $34.5 \%$ & $58.3 \%$ & $41.7 \%$ & $100 \%$ \\
\hline \multirow[t]{2}{*}{ Total } & Count & 196 & 154 & 181 & 169 & 115 & 235 & 350 \\
\hline & $\%$ & $56.0 \%$ & $44.0 \%$ & $51.7 \%$ & $48.3 \%$ & $32.9 \%$ & $67.1 \%$ & $100 \%$ \\
\hline
\end{tabular}


In addition, Table 10 demonstrates the results of applying Chi-Square test.

Table 10

The results of Chi-Square test for the effect of educational background

\begin{tabular}{|c|c|c|c|c|c|c|c|c|c|}
\hline & \multicolumn{3}{|c|}{ Personal } & \multicolumn{3}{|c|}{ Technical } & \multicolumn{3}{|c|}{ Management } \\
\hline & Value & df & Sig. (2-sided) & Value & df & Sig. (2-sided) & Value & df & Sig. (2-sided) \\
\hline Pearson Chi-Square & 9.279 & 3 & 0.026 & 9.155 & 3 & 0.027 & 13.380 & 3 & 0.004 \\
\hline Likelihood Ratio & 9.441 & 3 & 0.024 & 9.279 & 3 & 0.026 & 12.754 & 3 & 0.005 \\
\hline $\begin{array}{l}\text { Linear-by-Linear } \\
\text { Association }\end{array}$ & 5.291 & 1 & 0.021 & 0.421 & 1 & 0.516 & 3.607 & 1 & 0.058 \\
\hline $\mathrm{N}$ of Valid Cases & 350 & & & 350 & & & 350 & & \\
\hline
\end{tabular}

The results of Table 10 indicate that personal, technical and managerial barriers have meaningful correlations with educational backgrounds when the level of significance is five percent. In terms of personal barriers, social science maintains $50 \%$, in terms of technical barriers people with engineering background hold $65 \%$ and in terms of managerial barriers, people with engineering and social science maintain 77 and 69 percent correlation.

\section{Conclusion}

Building an efficient business unit requires efficient internal processes and this would never happen until we optimize all components of the system, properly. In this paper, we have presented an empirical investigation to detect important barriers in front of executing office automation systems. The proposed model of this paper designed a questionnaire consist of three parts including personal, technical and managerial barriers. In terms of personal barriers, lack of interest to use computer system is the most important personal factor and interest in using traditional system has received the lowest point. In terms of managerial barriers, lack of attention for training before installation has been the most important managerial factor and lack of users' participations in the design and development of systems has received the lowest point. Finally, in terms of technical barriers, inefficient and slow software package has been the most important technical factor.

We have also investigated the relationship of users' personal characteristics with three types of barriers. The results of our survey have indicated that personal and technical barriers had no correlations with gender but management barriers and gender were correlated when the level of significance was five percent. In addition, the results of our survey indicated that personal and technical barriers had meaningful correlations with job experience but management barriers and job experience was not correlated when the level of significance was five percent. Finally, the results of our survey have indicated that personal, technical and managerial barriers had meaningful correlations with educational backgrounds when the level of significance was five percent.

\section{Acknowledgment}

The authors would like to thank the anonymous referees for constructive comments on earlier version of this paper.

\section{References}

Charnes, A., Cooper, W.W., Rhodes, E. (1978). Measuring the efficiency of decision making units. European Journal of Operational Research, 2, 429-444.

Kaplan, R.S., \& Norton, D.P. (1996). Using the Balanced Scorecard as a Strategic Management System. Harvard Bussiness Review (January.February). 74(1), 75-85.

Kaplan, R.S., \& Norton, D.P. (2000). The strategy-focused organization: How balanced scorecard companies thrive in the new business environment. Harvard Bussiness School Press. 
Kaplan, R.S., \& Norton, D.P. (2004). Strategy maps: Converting intangible assets into tangible outcomes. Boston, MD: Harvard Bussiness School Press.

Khaki, A., Sadjadi, S., Azadeh, M \& Najafi, E. (2012). Ranking CCR-efficient units based on the indicator with limited resources. Decision Science Letters , 1(2), 87-95.

Mozaffari, A., Karkehabadi, H., Kheyrkhahan, M \& Karami, M. (2012). A development in balanced scorecard by designing a fuzzy and nonlinear Algorithm (case study: Islamic Azad university of Semnan). Management Science Letters, 2(5), 1819-1838.

Roghanian, E \& Foroughi, A. (2010). An empirical study of Iranian regional airports using robust data envelopment analysis. International Journal of Industrial Engineering Computations, 1(1), 65-72.

Zhou, Q., Huang, W., \& Zhang, Y. (2011). Identifying critical success factors in emergency management using a fuzzy DEMATEL method. Expert Systems with Applications, 49(2), 243-259. 